\title{
Individual social class, area-based deprivation, cardiovascular disease risk factors, and mortality: the Renfrew and Paisley study
}

\author{
George Davey Smith, Carole Hart, Graham Watt, David Hole, Victor Hawthorne
}

Department of Social Medicine, University of Bristol, Canynge Hall, Whiteladies Road, Bristol BS8 2PR G Davey Smith

Department of Public Health, University of Glasgow, Glasgow C Hart

Department of General Practice, University of Glasgow, Glasgow

G Watt

West of Scotland Cancer Surveillance Unit, Department of Public Health,

University of Glasgow, Glasgow

D Hole

The University of Michigan, School of Public Health, Department of Epidemiology, Ann Arbor, Michigan, USA V Hawthorne

Correspondence to: Professor Davey Smith.

\begin{abstract}
Objective-To investigate the associations of individual and area-based socioeconomic indicators with cardiovascular disease risk factors and mortality.

Design-Prospective study.

Setting-The towns of Renfrew and Paisley in the west of Scotland.

Participants-6961 men and 7991 women included in a population-based cardiovascular disease screening study between 1972 and 1976.

Main outcome measures-Cardiovascular disease risk factors and cardiorespiratory morbidity at the time of screening: 15 year mortality from all causes and cardiovascular disease.

Results-Both the area-based deprivation indicator and individual social class were associated with generally less favourable profiles of cardiovascular disease risk factors at the time of the baseline screening examinations. The exception was plasma cholesterol concentration, which was lower for men and women in manual social class groups. Independent contributions of areabased deprivation and individual social class were generally seen with respect to risk factors and morbidity. All cause and cardiovascular disease mortality rates were both inversely associated with socioeconomic position whether indexed by areabased deprivation or social class. The area-based and individual socioeconomic indicators made independent contributions to mortality risk.

Conclusions-Individually assigned and area-based socioeconomic indicators make independent contributions to several important health outcomes. The degree of inequalities in health that exist will not be demonstrated in studies using only one category of indicator. Similarly, adjustment for confounding by socioeconomic position in aetiological epidemiological studies will be inadequate if only one level of indicator is used. Policies aimed at reducing socioeconomic differentials in health should pay attention to the characteristics of the areas in which people live as well as the characteristics of the people who live in these areas.

(F Epidemiol Community Health 1998;52:399-405)
\end{abstract}

The association between social class, morbidity, and mortality is well established. ${ }^{12}$ Area-based indices of socioeconomic position, often referred to as "deprivation indices", have also been related to morbidity and mortality for the people to whom these indices are applied..$^{3-8}$ The choice of the use of an individually assigned marker of socioeconomic position or an area-based indicator is often made on the pragmatic grounds of data availability. The use of census level and individual level socioeconomic data have been shown to lead to associations of a similar magnitude between socioeconomic position and a variety of health measures, with the suggestion that area-based measures slightly underestimated the strength of the associations when compared with the associations of individually based socioeconomic measures and health. ${ }^{9}$

In some, ${ }^{9}{ }^{10}$ but not all, ${ }^{11}$ studies the use of larger geographical areas for the assignment of socioeconomic position leads to little, if any, attenuation in the magnitude of associations with health measures. This is surprising if areabased measures are considered merely to be proxy measures of individual socioeconomic position, as the level of misclassification would be expected to be greater when the size of area is larger. There are conceptual reasons as to why area-based measures may not simply function as indicators of individual socioeconomic position. Areas with a high level of socioeconomic disadvantage may also be disadvantaged with respect to transport, retail outlets, leisure facilities, environmental pollution, and social disorganisation, in ways that influence health independently of the socioeconomic characteristics of the people living in these areas. ${ }^{12}$ The demonstration of area-based effects would be important in emphasising the need to focus health promotion initiatives on the broader characteristics of places where disadvantaged people live, rather than simply on the people who live in these areas themselves.

The suggestion that the characteristics of area of residence have a particular influence on mortality risk is supported by two investigations that have examined both individual and area-based measures. ${ }^{13}{ }^{14} \mathrm{~A}$ study based on the Office of National Statistics (ONS) Longitudinal Study - a follow up of a $1 \%$ sample of the 1971 England and Wales census-indicated little influence of area-based deprivation once individual socioeconomic indicators had been taken into account. ${ }^{15}$ This study had several limitations, however. Firstly, no data on health status, health related behaviours or physiological risk factors were available. Secondly, the individual socioeconomic indicators were essentially the ones that were used to construct the area-based measure. There would therefore 
Table 1 Deprivation category by social class

\begin{tabular}{|c|c|c|c|c|c|c|c|}
\hline \multirow[b]{2}{*}{ Social class } & \multicolumn{6}{|c|}{ Deprivation category } & \multirow[b]{2}{*}{ Total (\%) } \\
\hline & 1 & 3 & 4 & 5 & 6 & 7 & \\
\hline \multicolumn{8}{|l|}{ Men } \\
\hline I & 76 & 83 & 72 & 78 & 38 & 2 & $349(5.0)$ \\
\hline II & 126 & 200 & 234 & 290 & 108 & 13 & $971(13.9)$ \\
\hline IIIN & 81 & 166 & 195 & 274 & 102 & 14 & $832(12.0)$ \\
\hline IIIM & 85 & 348 & 607 & 1144 & 528 & 98 & $2810(40.4)$ \\
\hline IV & 43 & 152 & 341 & 631 & 326 & 70 & $1563(22.5)$ \\
\hline $\mathrm{V}$ & 5 & 30 & 61 & 148 & 130 & 62 & $436(6.3)$ \\
\hline Total (\%) & $416(6.0)$ & $979(14.1)$ & $1510(21.7)$ & $2565(36.8)$ & $1232(17.7)$ & $259(3.7)$ & 6961 \\
\hline \multicolumn{8}{|l|}{ Women } \\
\hline I & 41 & 47 & 45 & 44 & 13 & 3 & $193(2.4)$ \\
\hline II & 152 & 235 & 311 & 370 & 158 & 31 & $1257(15.7)$ \\
\hline IIIN & 206 & 307 & 423 & 665 & 325 & 48 & $1974(24.7)$ \\
\hline IIIM & 59 & 191 & 324 & 558 & 287 & 71 & $1490(18.6)$ \\
\hline IV & 60 & 157 & 473 & 892 & 486 & 138 & $2206(27.6)$ \\
\hline $\mathrm{V}$ & 13 & 75 & 160 & 317 & 237 & 69 & $871(10.9)$ \\
\hline Total (\%) & $531(6.6)$ & $1012(12.7)$ & $1736(21.7)$ & $2846(35.6)$ & $1506(18.8)$ & $360(4.5)$ & 7991 \\
\hline
\end{tabular}

be strong correlations between individual and area-based measures as an automatic consequence of the nature of the data that were used.

The most commonly used individual socioeconomic indicator in British studies is Registrar General's occupational social class. In this study we investigate the independent contributions of occupational social class and deprivation level of area of residence to cardiovascular disease risk factors and mortality, using the screening and mortality follow up data of a large population-based health survey carried out in the west of Scotland between 1972 and 1976.

\section{Methods}

The Renfrew/Paisley general population study was carried out between 1972 and 1976, involving residents of the towns of Renfrew and Paisley who were aged 45-64 years. Full details of the study methodology have been reported previously. ${ }^{16}$ A response rate of $80 \%$ was obtained. A questionnaire was completed by each participant and this was checked when the participant attended a screening examination. The questionnaire recorded smoking habit, occupation, respiratory, and cardiovascular symptoms. Social class was determined by regular occupation, according to the Registrar General's classification. ${ }^{17}$ In the case of retired men, the last full time occupation was taken. For housewives and retired women, husbands' or fathers' occupations were used. Participants were classified as non-manual if they were in social classes I, II or IIIN and manual if in social classes IIIM, IV or V. Blood pressure, forced expiratory volume in one second $\left(\mathrm{FEV}_{1}\right)$, height, and weight were measured and an electrocardiogram was taken at the screening examination. A non-fasting blood sample was also taken to measure plasma cholesterol concentration.

The six lead electrocardiogram (leads I, II, III, aVR, aVL, and aVF) was taken with the subject sitting. Criteria for myocardial ischaemia on ECG were based on the Minnesota coding scheme. Any of the following codes were considered evidence of ischaemia, encompassing diagnoses of definite myocardial infarction, myocardial ischaemia, and left bundle branch block: 1.1-1.3, 4.1-4.4, 5.1-5.3, 7.1.
Angina was considered present if the definite or possible criteria of the Rose Angina Questionnaire were met. ${ }^{18}$

$\mathrm{FEV}_{1}$ relative to the predicted value was used to estimate impairment. Predicted values of $\mathrm{FEV}_{1}$ were obtained from linear regressions on age and height:

Predicted $\mathrm{FEV}_{1}$ for men $=-1.9302$

$-(0.0290 \times$ age $($ years $))+(0.0373 \times$ height (cm))

Predicted $\mathrm{FEV}_{1}$ for women $=-0.2662$

- $(0.0289 \times$ age $($ years $))+(0.0238 \times$ height (cm))

Coefficients were derived from a regression for the 878 men and 2796 women who had never smoked and who responded "no" to questions about bronchitis, breathing difficulties, and asthma. The $\mathrm{FEV}_{1}$, score (\%) was calculated as a percentage of actual $\mathrm{FEV}_{1} /$ predicted $\mathrm{FEV}_{1}$.

The home address at the time of screening was retrospectively postcoded, enabling deprivation category as defined by Carstairs and Morris to be ascertained, using 1981 census data. ${ }^{19}$ Deprivation category varies from 1 (least deprived) to 7 (most deprived) and is calculated from the deprivation score that is based on four variables derived from census data-male unemployment, overcrowding, car ownership, and proportion in social classes IV and V. Both postcode sector and enumeration district deprivation categories were analysed, with the results being very similar. As postcode sector deprivation category has been more often used in previous work we have reported on these results here. Fourteen postcode sectors were represented in the study population.

Some addresses could not be postcoded and assigned a deprivation category and some participants had given insufficient information on occupation to assign a social class. The analyses were therefore performed on 6961 (from 7058) men and 7991 (from 8353) women with complete data. Participants were flagged at the National Health Service Central Register in Edinburgh and notification of deaths have been received for a 15 year follow up period..$^{20}$ Cause of deaths were coded to ICD $9,{ }^{21}$ and cardiovascular disease (CVD) mortality consisted of deaths coded to ICD9 390-459. 
Table 2 Age adjusted means and proportions of baseline characteristics by deprivation category and social class

\begin{tabular}{|c|c|c|c|c|c|c|c|c|c|}
\hline & \multirow[b]{2}{*}{ All } & \multicolumn{6}{|c|}{ Deprivation category } & \multirow{2}{*}{$\begin{array}{l}\text { Trend test } \\
\text { adjusted for age }\end{array}$} & \multirow{2}{*}{$\begin{array}{l}\text { Trend test } \\
\text { adjusted for age } \\
\text { and social class }\end{array}$} \\
\hline & & 1 & 3 & 4 & 5 & 6 & 7 & & \\
\hline \multicolumn{10}{|l|}{ Men } \\
\hline Diastolic BP (mm Hg) & 86.1 & 85.3 & 87.0 & 84.5 & 87.1 & 84.8 & 87.9 & $\mathrm{p}=0.13$ & $\mathrm{p}=0.12$ \\
\hline Non-manual & 86.0 & 85.4 & 86.7 & 84.0 & 87.9 & 84.0 & 88.0 & & \\
\hline Manual & 86.1 & 85.1 & 87.3 & 84.8 & 86.8 & 85.1 & 87.9 & & \\
\hline Cholesterol (mmol/l) & 5.87 & 5.83 & 5.97 & 5.97 & 5.80 & 5.79 & 5.92 & $\mathrm{p}=0.0025$ & $\mathrm{p}=0.34$ \\
\hline Non-manual & 6.00 & 5.85 & 6.07 & 6.12 & 5.92 & 5.96 & 6.14 & & \\
\hline Manual & 5.81 & 5.77 & 5.88 & 5.90 & 5.76 & 5.75 & 5.89 & & \\
\hline Height $(\mathrm{cm})$ & 169.5 & 171.4 & 171.1 & 170.1 & 169.2 & 168.3 & 166.7 & $\mathrm{p}=0.0001$ & $\mathrm{p}=0.0001$ \\
\hline Non-manual & 171.5 & 171.9 & 172.1 & 171.9 & 171.0 & 170.6 & 166.7 & & \\
\hline Manual & 168.7 & 170.4 & 170.2 & 169.2 & 168.6 & 167.7 & 166.7 & & \\
\hline Body mass index $\left(\mathrm{kg} / \mathrm{m}^{2}\right)$ & 25.9 & 25.9 & 25.7 & 25.8 & 26.0 & 26.0 & 25.4 & $\mathrm{p}=0.83$ & $\mathrm{p}=0.67$ \\
\hline Non-manual & 25.9 & 25.7 & 25.8 & 25.9 & 26.0 & 26.3 & 25.5 & & \\
\hline Manual & 25.8 & 26.4 & 25.6 & 25.7 & 25.9 & 25.9 & 25.4 & & \\
\hline $\mathrm{FEV}_{1}$ score $(\%)$ & 88.6 & 94.9 & 91.6 & 88.9 & 88.1 & 86.9 & 78.1 & $\mathrm{p}=0.0001$ & $\mathrm{p}=0.0001$ \\
\hline Non-manual & 92.9 & 96.9 & 93.9 & 93.0 & 92.0 & 89.7 & 84.8 & & \\
\hline Manual & 86.7 & 90.6 & 89.5 & 86.8 & 86.8 & 86.3 & 77.3 & & \\
\hline$\%$ Current smokers & 58.6 & 46.9 & 48.8 & 57.4 & 61.3 & 62.8 & 72.0 & $\mathrm{p}=0.0001$ & $\mathrm{p}=0.0001$ \\
\hline Non-manual & 49.7 & 44.3 & 44.1 & 49.1 & 53.7 & 53.5 & 75.4 & & \\
\hline Manual & 62.6 & 53.1 & 52.9 & 61.5 & 63.8 & 65.2 & 72.1 & & \\
\hline$\%$ Ex smokers & 24.7 & 32.2 & 29.8 & 25.4 & 23.1 & 22.3 & 16.2 & $\mathrm{p}=0.0001$ & $\mathrm{p}=0.0001$ \\
\hline Non-manual & 29.3 & 33.1 & 33.0 & 30.2 & 26.6 & 26.0 & 16.2 & & \\
\hline Manual & 22.6 & 29.5 & 27.3 & 23.1 & 22.0 & 21.4 & 16.3 & & \\
\hline$\%$ MRC bronchitis & 5.9 & 3.0 & 4.2 & 6.3 & 6.1 & 6.5 & 9.3 & $\mathrm{p}=0.0001$ & $\mathrm{p}=0.022$ \\
\hline Non-manual & 3.1 & 2.5 & 2.5 & 3.3 & 3.7 & 3.3 & 1.9 & & \\
\hline Manual & 7.1 & 3.7 & 5.5 & 7.9 & 6.9 & 7.3 & 10.5 & & \\
\hline$\%$ Angina & 17.6 & 12.4 & 15.9 & 17.3 & 18.1 & 18.1 & 27.8 & $\mathrm{p}=0.0001$ & $\mathrm{p}=0.0003$ \\
\hline Non-manual & 14.3 & 11.8 & 13.4 & 12.9 & 15.8 & 16.2 & 42.9 & & \\
\hline Manual & 19.2 & 13.6 & 17.9 & 19.5 & 18.8 & 18.6 & 28.6 & & \\
\hline$\% \mathrm{ECG}$ ischaemia & 10.5 & 6.9 & 11.2 & 10.8 & 11.3 & 9.2 & 11.3 & $\mathrm{p}=0.24$ & $\mathrm{p}=0.17$ \\
\hline Non-manual & 10.9 & 8.2 & 14.2 & 11.5 & 11.3 & 6.1 & 37.6 & & \\
\hline Manual & 10.3 & 3.9 & 8.7 & 10.4 & 11.2 & 10.0 & 11.2 & & \\
\hline \multicolumn{10}{|l|}{ Women } \\
\hline Diastolic BP (mm Hg) & 85.1 & 85.0 & 86.3 & 83.1 & 86.3 & 84.5 & 85.3 & $\mathrm{p}=0.60$ & $\mathrm{p}=0.67$ \\
\hline Non-manual & 84.3 & 85.0 & 85.8 & 82.2 & 85.7 & 82.7 & 83.9 & & \\
\hline Manual & 85.7 & 85.2 & 87.0 & 83.8 & 86.7 & 85.5 & 85.7 & & \\
\hline Cholesterol (mmol/l) & 6.43 & 6.36 & 6.49 & 6.50 & 6.43 & 6.35 & 6.35 & $\mathrm{p}=0.007$ & $\mathrm{p}=0.12$ \\
\hline Non-manual & 6.50 & 6.41 & 6.50 & 6.61 & 6.48 & 6.46 & 6.51 & & \\
\hline Manual & 6.38 & 6.21 & 6.48 & 6.41 & 6.40 & 6.30 & 6.31 & & \\
\hline Height $(\mathrm{cm})$ & 157.7 & 160.2 & 158.2 & 158.1 & 157.2 & 157.4 & 155.8 & $\mathrm{p}=0.0001$ & $\mathrm{p}=0.0001$ \\
\hline Non-manual & 159.0 & 160.3 & 159.1 & 159.5 & 158.4 & 158.2 & 157.7 & & \\
\hline Manual & 156.8 & 159.8 & 157.0 & 157.0 & 156.5 & 157.0 & 155.3 & & \\
\hline Body mass index $\left(\mathrm{kg} / \mathrm{m}^{2}\right)$ & 25.8 & 24.8 & 25.5 & 25.6 & 26.0 & 26.0 & 25.9 & $\mathrm{p}=0.0001$ & $\mathrm{p}=0.005$ \\
\hline Non-manual & 25.2 & 24.7 & 25.1 & 25.1 & 25.5 & 25.3 & 24.9 & & \\
\hline Manual & 26.2 & 25.4 & 26.1 & 26.0 & 26.3 & 26.4 & 26.2 & & \\
\hline $\mathrm{FEV}_{1}$ score $(\%)$ & 92.5 & 99.3 & 96.8 & 93.0 & 92.4 & 89.1 & 81.6 & $\mathrm{p}=0.0001$ & $\mathrm{p}=0.0001$ \\
\hline Non-manual & 96.7 & 100.7 & 98.5 & 96.8 & 96.0 & 94.0 & 87.3 & & \\
\hline Manual & 89.3 & 95.0 & 94.4 & 89.9 & 90.3 & 86.7 & 79.9 & & \\
\hline$\%$ Current smokers & 46.8 & 34.3 & 37.5 & 45.3 & 48.9 & 51.5 & 60.8 & $\mathrm{p}=0.0001$ & $\mathrm{p}=0.0001$ \\
\hline Non-manual & 43.1 & 33.4 & 37.5 & 41.9 & 47.0 & 47.2 & 62.0 & & \\
\hline Manual & 49.9 & 37.0 & 38.5 & 48.3 & 50.4 & 53.7 & 60.2 & & \\
\hline$\%$ Ex smokers & 7.5 & 11.7 & 7.8 & 8.3 & 6.8 & 6.9 & 5.1 & $\mathrm{p}=0.0001$ & $\mathrm{p}=0.003$ \\
\hline Non-manual & 8.8 & 11.8 & 9.5 & 9.4 & 7.8 & 7.6 & 3.7 & & \\
\hline Manual & 6.4 & 11.9 & 5.1 & 7.2 & 6.1 & 6.6 & 5.6 & & \\
\hline$\%$ MRC bronchitis & 4.0 & 1.9 & 2.4 & 3.2 & 3.9 & 6.1 & 7.7 & $\mathrm{p}=0.0001$ & $\mathrm{p}=0.0001$ \\
\hline Non-manual & 2.3 & 2.0 & 1.0 & 2.0 & 2.6 & 4.0 & 5.1 & & \\
\hline Manual & 5.3 & 1.2 & 4.4 & 4.0 & 4.8 & 7.1 & 8.4 & & \\
\hline$\%$ Angina & 16.9 & 11.4 & 15.6 & 14.9 & 18.2 & 18.9 & 19.7 & $\mathrm{p}=0.0001$ & $\mathrm{p}=0.0002$ \\
\hline Non-manual & 14.0 & 10.5 & 13.0 & 14.3 & 15.4 & 15.5 & 10.0 & & \\
\hline Manual & 19.1 & 13.3 & 19.1 & 15.3 & 19.8 & 20.6 & 22.7 & & \\
\hline$\% \mathrm{ECG}$ ischaemia & 10.0 & 8.5 & 9.6 & 10.1 & 9.8 & 10.0 & 13.1 & $\mathrm{p}=0.018$ & $\mathrm{p}=0.028$ \\
\hline Non-manual & 9.0 & 7.2 & 9.4 & 8.9 & 8.6 & 10.1 & 12.2 & & \\
\hline Manual & 10.6 & 11.6 & 10.5 & 10.8 & 10.5 & 9.9 & 13.0 & & \\
\hline
\end{tabular}

Age adjusted means for continuous variables were calculated using PROC GLM of the SAS system $^{22}$ with tests for trend being obtained with the PROC REG program. Categorical variables were age standardised by the direct method, using the male and female study populations as the standard and tests for trend were obtained with the PROC LOGIST program. Age adjusted death rates were calculated using a person years at risk based lifetable approach and age standardisation was by the direct method. Trend tests were obtained through proportional hazards regression using PROC PHREG, with age and deprivation score or social class coded as continuous variables. Adjustments were made using social class at six levels and deprivation score, both as continuous variables. Proportional hazards coefficients and their standard errors were calculated using Cox's model. Adjustment for age and other risk factors was performed by including terms for these in the models. Adjustment for smoking was for the number of cigarettes smoked per day, together with a term for ex-smokers. Exponentiated hazards coefficients were taken as indicators of relative rates of mortality.

\section{Results}

No postcode sectors in Renfrew and Paisley were in deprivation category 2 and few participants lived in deprivation categories 1 and 7, the majority living in categories 4 and 5. Tabulation of social class derived from occupation with deprivation category showed that each 
Table 3 Fifteen year age adjusted death rates by deprivation category

\begin{tabular}{|c|c|c|c|c|c|c|c|}
\hline & \multicolumn{6}{|c|}{ Deprivation category } & \multirow[b]{2}{*}{ Trend } \\
\hline & 1 & 3 & 4 & 5 & 6 & 7 & \\
\hline \multicolumn{8}{|l|}{ Men } \\
\hline \multicolumn{8}{|l|}{ All cause } \\
\hline No of deaths & 107 & 246 & 445 & 801 & 424 & 110 & \\
\hline Death rate & 165.7 & 178.8 & 200.5 & 218.3 & 228.8 & 292.2 & $\mathrm{p}=0.0001$ \\
\hline \multicolumn{8}{|c|}{ Cardiovascular disease } \\
\hline No of deaths & 59 & 137 & 241 & 436 & 208 & 62 & \\
\hline Death rate & 98.7 & 109.6 & 118.6 & 132.6 & 127.1 & 184.8 & $\mathrm{p}=0.0001$ \\
\hline \multicolumn{8}{|l|}{ Women } \\
\hline \multicolumn{8}{|l|}{ All cause } \\
\hline No of deaths & 78 & 165 & 291 & 539 & 344 & 75 & \\
\hline Death rate & 97.5 & 114.2 & 113.5 & 131.2 & 147.1 & 137.6 & $\mathrm{p}=0.0001$ \\
\hline \multicolumn{8}{|c|}{ Cardiovascular disease } \\
\hline No of deaths & 41 & 70 & 140 & 268 & 169 & 38 & \\
\hline Death rate & 52.5 & 53.8 & 58.8 & 71.1 & 76.9 & 75.2 & $\mathrm{p}=0.002$ \\
\hline
\end{tabular}

Table 4 Relative rates (95\% confidence intervals) of mortality by deprivation category

\begin{tabular}{|c|c|c|c|c|}
\hline & \multicolumn{3}{|c|}{ Deprivation category } & \multirow[b]{2}{*}{ Trend } \\
\hline & $1-3$ & $4-5$ & $6-7$ & \\
\hline \multicolumn{5}{|l|}{ Men } \\
\hline \multicolumn{5}{|l|}{ All cause } \\
\hline Age & 1 & $1.27(1.12,1.42)$ & $1.47(1.28,1.68)$ & $\mathrm{p}=0.0001$ \\
\hline Age + social class & 1 & $1.19(1.06,1.35)$ & $1.34(1.17,1.54)$ & $\mathrm{p}=0.0001$ \\
\hline Age + risk factors ${ }^{\star}$ & 1 & $1.12(1.00,1.26)$ & $1.24(1.08,1.42)$ & $\mathrm{p}=0.0008$ \\
\hline \multicolumn{5}{|l|}{ Cardiovascular disease } \\
\hline Age & 1 & $1.24(1.06,1.45)$ & $1.33(1.11,1.60)$ & $\mathrm{p}=0.0001$ \\
\hline Age + social class & 1 & $1.19(1.01,1.40)$ & $1.26(1.04,1.52)$ & $\mathrm{p}=0.0001$ \\
\hline Age + risk factors $\star$ & 1 & $1.12(0.95,1.31)$ & $1.19(0.98,1.43)$ & $\mathrm{p}=0.019$ \\
\hline \multicolumn{5}{|l|}{ Women } \\
\hline \multicolumn{5}{|l|}{ All cause } \\
\hline Age & 1 & $1.18(1.03,1.37)$ & $1.40(1.19,1.64)$ & $\mathrm{p}=0.0001$ \\
\hline Age + social class & 1 & $1.12(0.97,1.30)$ & $1.29(1.10,1.52)$ & $\mathrm{p}=0.006$ \\
\hline Age + risk factors $\star$ & 1 & $1.07(0.93,1.24)$ & $1.16(0.99,1.36)$ & $\mathrm{p}=0.55$ \\
\hline \multicolumn{5}{|l|}{ Cardiovascular disease } \\
\hline Age & 1 & $1.28(1.04,1.58)$ & $1.48(1.17,1.86)$ & $\mathrm{p}=0.0002$ \\
\hline Age + social class & 1 & $1.18(0.96,1.47)$ & $1.33(1.05,1.69)$ & $\mathrm{p}=0.035$ \\
\hline Age + risk factors ${ }^{\star}$ & 1 & $1.15(0.93,1.42)$ & $1.21(0.95,1.52)$ & $\mathrm{p}=0.60$ \\
\hline
\end{tabular}

${ }^{\star}$ Risk factors are diastolic blood pressure, cholesterol, body mass index, $\mathrm{FEV}_{1}$ score, smoking, angina, ECG ischaemia, and bronchitis.

deprivation category had representatives from each social class (table 1). There were small numbers of men and women from social class I living in deprivation category 7 and small numbers from social class $\mathrm{V}$ living in deprivation category 1 .

Table 2 shows the baseline risk factors by deprivation category and social class. Clear relations were seen between height, $\mathrm{FEV}_{1}$, cholesterol concentration, smoking, bronchitis, angina, and deprivation category for both men and women. Body mass index and ECG ischaemia were associated with deprivation category only for women. With the exception of cholesterol concentration these associations remained after adjustment for social class. Within each deprivation category, manual and non-manual groups had differing levels of risk factors. Male and female manual social class participants had lower cholesterol concentrations, were shorter, had lower $\mathrm{FEV}_{1}$, were more likely to smoke and have bronchitis and angina than the non-manual social class participants. Manual women had higher diastolic blood pressure and body mass index and had more ECG ischaemia than non-manual women. The associations between social class and risk factors were little changed by adjustment for deprivation (results available from the authors).

Death rates (table 3) show significant trends with deprivation category for all cause and CVD mortality for men and women. Death rates for men in deprivation category 7 were almost double the rates for men in deprivation category 1. For men and women all cause and CVD mortality retained sizeable and significant associations with deprivation after adjustment for social class (table 4). Adjustment for risk factors attenuated the associations, reducing them to non-significance for women. Social class differences in all cause and CVD mortality in men and women were attenuated but remained substantial and statistically significant after adjustment for deprivation score (table 5). Adjustment for risk factors caused greater attenuation of social class differences in mortality than did adjustment for deprivation score. Formal tests of interaction between social class and deprivation score were not statistically significant.

All cause mortality was further analysed by division of each deprivation category into nonmanual and manual social classes. Taking the baseline category as non-manual workers living in deprivation category 1 , the risk increased across deprivation category within both nonmanual and manual social classes for men (table 6). Additionally, manual groups had a

Table 5 Relative rates (95\% confidence intervals) of mortality by social class

\begin{tabular}{|c|c|c|c|c|c|}
\hline & \multicolumn{4}{|c|}{ Social class } & \multirow[b]{2}{*}{ Trend } \\
\hline & I and II & IIIN & IIIM & IV and $V$ & \\
\hline \multicolumn{6}{|l|}{ Men } \\
\hline \multicolumn{6}{|l|}{ All cause } \\
\hline Age & 1 & $1.25(1.06,1.47)$ & $1.40(1.23,1.60)$ & $1.52(1.33,1.74)$ & $\mathrm{p}=0.0001$ \\
\hline Age + deprivation score & 1 & $1.23(1.04,1.45)$ & $1.32(1.16,1.51)$ & $1.41(1.23,1.62)$ & $\mathrm{p}=0.0001$ \\
\hline Age + risk factors ${ }^{\star}$ & 1 & $1.13(0.96,1.34)$ & $1.18(1.03,1.34)$ & $1.22(1.06,1.40)$ & $\mathrm{p}=0.005$ \\
\hline \multicolumn{6}{|l|}{ Cardiovascular disease } \\
\hline Age & 1 & $1.23(0.99,1.54)$ & $1.35(1.13,1.60)$ & $1.33(1.11,1.60)$ & $\mathrm{p}=0.002$ \\
\hline Age + deprivation score & 1 & $1.21(0.97,1.52)$ & $1.27(1.07,1.52)$ & $1.24(1.03,1.49)$ & $\mathrm{p}=0.033$ \\
\hline Age + risk factors ${ }^{\star}$ & 1 & $1.13(0.90,1.41)$ & $1.20(1.01,1.44)$ & $1.16(0.96,1.39)$ & $\mathrm{p}=0.13$ \\
\hline \multicolumn{6}{|l|}{ Women } \\
\hline \multicolumn{6}{|l|}{ All cause } \\
\hline Age & 1 & $0.92(0.77,1.10)$ & $1.38(1.17,1.64)$ & $1.32(1.14,1.54)$ & $\mathrm{p}=0.0001$ \\
\hline Age + deprivation score & 1 & $0.91(0.77,1.09)$ & $1.35(1.14,1.60)$ & $1.27(1.09,1.49)$ & $\mathrm{p}=0.0001$ \\
\hline Age + risk factors ${ }^{\star}$ & 1 & $0.93(0.78,1.11)$ & $1.21(1.02,1.44)$ & $1.13(0.97,1.33)$ & $\mathrm{p}=0.014$ \\
\hline \multicolumn{6}{|l|}{ Cardiovascular disease } \\
\hline Age & 1 & $0.88(0.68,1.15)$ & $1.44(1.12,1.84)$ & $1.50(1.20,1.87)$ & $\mathrm{p}=0.0001$ \\
\hline Age + deprivation score & 1 & $0.87(0.67,1.14)$ & $1.40(1.09,1.79)$ & $1.44(1.15,1.80)$ & $\mathrm{p}=0.0001$ \\
\hline Age + risk factors ${ }^{\star}$ & 1 & $0.90(0.69,1.17)$ & $1.19(0.93,1.53)$ & $1.25(0.99,1.56)$ & $\mathrm{p}=0.005$ \\
\hline
\end{tabular}

${ }^{\star}$ Risk factors are diastolic blood pressure, cholesterol, body mass index, $\mathrm{FEV}_{1}$ score, smoking, angina, ECG ischaemia, and bronchitis. 
Table 6 Age adjusted relative risk (95\% confidence intervals) for all cause mortality by deprivation category and social class

\begin{tabular}{|c|c|c|c|c|c|c|}
\hline & \multicolumn{6}{|c|}{ Deprivation category } \\
\hline & 1 & 3 & 4 & 5 & 6 & 7 \\
\hline \multicolumn{7}{|l|}{ Men } \\
\hline Non-manual & 1 & $1.06(0.78,1.44)$ & $1.02(0.75,1.37)$ & $1.26(0.95,1.67)$ & $1.43(1.03,1.98)$ & $1.70(0.94,3.08)$ \\
\hline $\begin{array}{l}\text { Manual } \\
\text { Women }\end{array}$ & $1.17(0.79,1.73)$ & $1.22(0.92,1.64)$ & $1.47(1.13,1.92)$ & $1.56(1.21,2.01)$ & $1.57(1.21,2.04)$ & $2.28(1.67,3.11)$ \\
\hline Non-manual & 1 & $1.05(0.75,1.48)$ & $1.01(0.73,1.40)$ & $1.18(0.87,1.59)$ & $1.40(1.00,1.95)$ & $0.94(0.49,1.80)$ \\
\hline Manual & $1.07(0.65,1.76)$ & $1.47(1.05,2.06)$ & $1.40(1.04,1.88)$ & $1.62(1.23,2.15)$ & $1.77(1.32,2.36)$ & $1.67(1.17,2.39)$ \\
\hline
\end{tabular}

higher risk than non-manual groups for each deprivation category. For women manual groups had a higher mortality risk than non manual groups for each deprivation category and a clear association between deprivation category and mortality was seen among manual, but not non-manual, women.

\section{Discussion}

The population covered in this study all reside within the Renfrew district, an area that includes rural, new town, and commuter populations. The 0-64 year age band standardised mortality ratio in 1980-85 for Renfrew district was 107 , with Scotland as the standard. ${ }^{19}$ The area covered by the Renfrew and Paisley study represents the more deprived parts of the Renfrew district, and includes the postcode sector with the highest deprivation score in Scotland. ${ }^{19}$ This study therefore covers a representative sample from a largely deprived area, and is unusual in this regard for UK epidemiological studies. $^{23-25}$

Within this area of high overall deprivation there was still considerable heterogeneity of both individual social class and area-based deprivation measures. Large differences in cardiovascular disease risk factors by individual social class and area-based deprivation are seen. These generally ran in the same direction, with less favourable socioeconomic position, assigned by either individual or area-based measures, being accompanied by shorter height, worse lung function, and higher prevalences of bronchitis and coronary heart disease. The two socioeconomic measures contributed independently to the distribution of these health related measures. For women, but not men, body mass index was higher in the groups in less favourable social circumstances, in keeping with other data on the social distribution of obesity. ${ }^{26}$ Plasma cholesterol concentrations were higher in the nonmanual social class groups in this study, in line with other investigations carried out at around the same time, ${ }^{23}{ }^{24}$ although this direction of association has not previously been reported for women in the UK, for whom data are sparse. The higher body mass index in women from manual social groups would be expected to lead to higher circulating cholesterol concentrations, and clearly some other factor is involved in determining the distribution of cholesterol concentrations.

A few studies have examined the contribution of individual and area-based socioeconomic characteristics to the distribution of health related behaviours. Multilevel modelling approaches have generally identified effects of residential area on smoking behaviour and alcohol consumption, ${ }^{27}{ }^{28}$ together with influences on physiological risk factors such as blood pressure and circulating cholesterol concentration that are responsive to health related behaviours. These area effects tend to be considerably smaller than the effects of individual socioeconomic position, but the categorisation of the areas has not been one that has explicitly focused on their socioeconomic characteristics. A study in Glasgow that investigated health related behaviours and physical measurements in relation to individual social class and social characteristics of area of residence found that poorer areas contained people who were less likely to consume (and had less access to) healthy foods, less likely to participate in sport, more likely to be smokers, to be shorter, have higher body mass indices and greater waist to hip ratios. ${ }^{29} 30$ Our analyses suggest that the inhabitants of deprived areas are more likely to be smokers, have poor lung function, be shorter and, for women, have higher body mass indices, even after the occupational social class of these people has been taken into account.

Geographical differences in mortality that are independent of individual socioeconomic characteristics can be seen in international comparisons or in broad geographical differences within a country (for example, north versus south in England and Wales). ${ }^{31}{ }^{32}$ Few investigations of individual and area-based socioeconomic measures in relation to mortality among subjects have been carried out, however. Carstairs and Morris demonstrate consistent gradients in mortality by deprivation level within social class groups, while the reverse is not the case. This suggests that an important area of residence effect exists. ${ }^{14}$ In the Scottish Heart Health Study both an area-based deprivation indicator and individual social class were associated with prevalent coronary heart disease, with both remaining significant predictors in a multivariable model. ${ }^{33}$ In the US National Longitudinal Mortality Study median family income for census tract of residence and individual family income have been related to mortality. While larger mortality differentials were seen in relation to individual family income, individual and area-based measures made independent contributions to mortality risk among people of working age. ${ }^{34}$ In the England and Wales Longitudinal Study an areabased deprivation indicator showed little influence on mortality once the constituents of the indicator had been adjusted for at the individual level. ${ }^{15}$ These latter two studies suffer from the conceptual problem of using identical markers at an aggregate and individual level. If specific 
influences of place type are considered to exist then their particularity may better be indicated by variables other than those considered at the individual level. Indeed a re-analysis of the England and Wales Longitudinal Study using the Craig-Webber area classification demonstrated an independent contribution of area characteristics after individual socioeconomic indicators had been taken into account. ${ }^{35}$

In our data, as in the similar analyses carried out for the Alameda County Study, ${ }^{136}$ an independent, but attenuated, association between area-based deprivation and all cause mortality was seen after adjustment for an extensive array of risk factors. In our data this was only seen for men, while multivariable analyses were only carried out for both sexes combined in the Alameda County Study. It could be considered that misclassification in the risk factor data will lead to underadjustment and that with better data the already substantial attenuation in the association between area-based deprivation and mortality brought about through risk factor adjustment would be even greater. Alternatively, the unequal distribution of risk factors according to socioeconomic characteristics of areas of residence could be considered to mediate between area and health, rather than confound the association. In this case the multivariable adjustments we have carried out could be considered to represent over-adjustment.

In this study, as in the Alameda County Study, data on socioeconomic position in adulthood were available, but data on childhood socioeconomic circumstances were not. In a further study in the west of Scotland adjustment for a cumulative socioeconomic indicator, based on social circumstances from childhood through to adulthood, led to considerable attenuation of the association between deprivation level of area of residence and mortality among men. ${ }^{37}$ Cumulative lifecourse socioeconomic measures will reflect other factors than socially patterned exposures in adulthood. Firstly, there may be direct influences of childhood socioeconomic deprivation on mortality from various causes in adulthood. ${ }^{37} 38$ Secondly, socioeconomic position in adulthood and area of residence may both be influenced by educational achievement and other factors influencing geographical mobility. Several calls have been made regarding the necessity to consider geography as an additional dimension in studies of variations in health. ${ }^{123639}$ This call should be extended to one that recognises the need to include a temporal dimension in addition to current socioeconomic position and residential area of people.

CONCEPTUAL ISSUES IN THE USE OF AREA-BASED SOCIOECONOMIC INDICATORS

When using area-based indicators of socioeconomic position two forms of bias could be introduced. ${ }^{70}$ It could be considered that the area-based measure serves as a proxy indicator of individual socioeconomic circumstances. In this instance the associations between areabased socioeconomic measures and health outcomes would be underestimates of underlying
KEY POINTS

- Individual and area-based socioeconomic measures are independently associated with risk factors, morbidity, and mortality.

- The use of single socioeconomic indicators as control variables in epidemiological studies will leave considerable residual confounding.

- The use of single socioeconomic indicators does not allow full description of the degree of health inequalities.

associations between individual socioeconomic position and health, as considerable misclassification of individual socioeconomic circumstances by the area-based measure would occur. The use of larger geographical areas should lead to greater misclassification of individual socioeconomic position and therefore to the associations between the area-based indicator and health outcomes being attenuated estimates of the underlying association between individual socioeconomic position and health. Conversely, there may be specific characteristics of the areas that influence health in other ways than through individual socioeconomic differences. Technically, the residuals from analyses using individual level data will be correlated with the area-based indicator. ${ }^{40}{ }^{41}$ In this case if the area-based measure is used as a proxy for individual socioeconomic position it could overestimate, rather than underestimate, the magnitude of individual level associations. Area-based measures will, however, provide additional information on the socioeconomic characteristics of residents within the area, independent of the individual socioeconomic circumstances of these people.

The empirical findings with respect to these questions have been variable and have depended upon the context of studies and the health outcomes under examination. ${ }^{9} 101140$ The contextual effects of areas, and the size of areas that determine these effects, will differ in different places and for different health outcomes, so this inconsistency in the literature is not unexpected.

The particular aspects of different areas that may influence health independently of individual social class are currently under investigation. ${ }^{12} 3642 \mathrm{~A}$ range of such characteristics, including environmental effects, housing conditions, social disorganisation, transport, insecurity about personal safety, the availability of retail and leisure facilities, socially determined health related behaviours, and access to health care, have been implicated in this regard. Further investigation of this issue, both qualitative and quantitative, is required if our current understanding is to be taken forward.

\section{IMPLICATIONS AND CONCLUSIONS}

A wide range of characteristics of areas that reflect their broader social constitution, while not being simply reducible to the socioeconomic characteristics of the people living in 
these areas, have been related to mortality. This includes such factors as socioeconomic inequality within the areas, voting patterns at elections, crime rates, education and medical care expenditure and welfare services. ${ }^{43-46}$ However, studies to date-including our own-have tended to use socioeconomic indicators that have essentially the same meaning at aggregate and individual level. Further investigation of a wider range of socioeconomic and sociocultural characteristics of areas should be undertaken.

Individually assigned and area-based socioeconomic indicators make independent contributions to at least some important health outcomes. The use of either indicator alone when attempting to adjust for socioeconomic confounding in aetiological epidemiological studies may leave a substantial degree of residual confounding. Similarly the use of only one kind of indicator will not fully describe the degree of inequalities in health that exist. Both areabased and individually-based socioeconomic data should be collected where possible and social circumstances acting across the lifecourse, rather than just at one stage, require consideration.

Funding: The Scottish Home and Health Department supported work on the Renfrew and Paisley cohort.

ported work on the Renfrew

1 Davey Smith G, Bartley M, Blane D. The Black Report on socio-economic inequalities in health 10 years on. $B M \mathcal{F}$ 1990;301:373-7.

2 Davey Smith G, Bartley M, Blane D. Explanations for socio-economic differentials in mortality: evidence from socio-economic differentials in mortality: evidence from

3 Phillimore P, Beattie A, Townsend P. Widening inequality of health in northern England, 1981-91. BMF 1994;308: health in

4 McCarron PG, Davey Smith G, Womersley JJ. Deprivation and mortality in Glasgow: changes from 1980 to 1992. BMF 1994;309:1481-2.

5 McLoone P, Boddy FA. Deprivation and mortality in Scotland, 1981 and 1991. BMF 1994;309:1465-70

6 Eachus J, Williams M, Chan P, et al. Deprivation and causespecific Morbidity: Evidence from the Somerset and Avon Survey of Health. BMF 1996;312:287-92.

7 Davey Smith G, Neaton JD, Wentworth D, et al. Socio-economic Differentials in mortality risk among men screened for the Multiple Risk Factor Intervention Trial: Part I - results for 300,685 white men. Am f Public Health 1996;86:486-96.

8 Davey Smith G, Wentworth D, Neaton JD, et al. Socio-economic differentials in mortality risk among men Socio-economic differentials in mortality risk among men
screened for the Multiple Risk Factor Intervention Trial: screened for the Multiple Risk Factor Intervention Trial: Part II - results for

9 Krieger N. Overcoming the absence of socio-economic data in medical records: validation and application of a censusbased methodology. Am f Public Health 1992;82:703-10.

10 Carr-Hill R, Rice N. Is enumeration district level an improvement on ward level analysis in studies of deprivation and health? $\mathcal{F}$ Epidemiol Community Health 1995;49 (suppl 2):28-9.

11 Hyndman JCG, Holman CDJ, Hockey RL, et al. Risk classification of social disadvantage based on geographical areas: comparison of postcode and collector's district analyses. Int f Epidemiol 1995;24:165-76.

12 Macintyre S, MacIver S, Sooman A. Area, class and health: should we be focusing on places or people? Fournal of Social Policy 1993;22:213-34.

13 Haan M, Kaplan GA, Camacho T. Poverty and health: prospective evidence from the Alameda County study. Am $\mathcal{F}$ spective evidence from the

14 Carstairs V, Morris R. Deprivation and mortality: an alternative to social class? Community Medicine 1989;11: 210-19.

15 Sloggett A, Joshi H. Higher mortality in deprived areas: community or personal disadvantage. BMF 1994;309: 1470-4.
16 Hawthorne VM, Watt GCM, Hart CL, et al. Cardiorespiratory disease in men and women in urban Scotland: Baseline characteristics of the Renfrew/Paisley (MIDSPAN) study population. Scott Med f 1995;40:102-7.

17 General Register Office. Classification of occupations 1966. London: HMSO, 1966

18 Hart CL, Watt GCM, Davey Smith G, et al. Pre-existing ischaemic heart disease and ischaemic heart disease mortality in women compared with men. Int $\mathcal{f}$ Epidemiol 1997;26:508-15.

19 Carstairs V, Morris R. Deprivation and health in Scotland. Aberdeen: Aberdeen University Press, 1991.

20 Watt GCM, Hart CL, Hole DJ, et al. Risk factors for cardiorespiratory and all cause mortality in men and women in urban Scotland: 15 year follow up. Scott Med $71995 ; 40$. $108-12$.

21 World Health Organisation. Classification of diseases 9th revision. Geneva: WHO, 1977.

22 SAS Institute. SAS language and procedures: usage 2, version 6. Cary, NC: SAS Institute, 1991.

23 Davey Smith G, Shipley MJ, Rose G. The magnitude and causes of socio-economic differentials in mortality: further evidence from the Whitehall study. F Epidemiol Community Health 1990;44:265-70.

24 Pocock SJ, Shaper AG, Cook DG, et al. Social class differences in ischaemic heart disease in British men. Lancet 1987;ii: 197-201.

25 Smith WCS, Tunstall-Pedoe H, Crombie IK, et al. Concomitants of excess coronary deaths - major risk factor and lifestyle findings from 10,359 men and women in the Scottish Heart Health Study. Scott Med f 1989;34:550-5.

26 Davey Smith G, Brunner E. Socio-economic differentials in health: the role of nutrition. Proceedings of the Nutrition Society 1977;56:75-90.

27 Duncan C, Jones K, Moon G. Do places matter? A multilevel analysis of regional variations in health-related behaviour in Britain. Soc Sci Med 1993;37:725-35.

28 Hart C, Ecob R, Davey Smith G. People, places and Coronary Heart Disease risk factors: a multilevel analysis of the Scottish Heart Health Study Archive. Soc Sci Med 1997;45: 893-902.

29 Ellaway A, Macintyre S. Does where you live predict health related behaviours?: A case study in Glasgow. Health Bull (Edinb) 1996;54:443-6.

30 Ellaway A, Anderson A, Macintyre S. Does area of residence affect body size and shape? Int f Obes 1997;21:304-8.

31 Wilkinson R. Unhealthy societies: the afflictions of inequality. London: Routledge, 1996.

32 Martin WJ. The distribution in England and Wales of mortality from coronary disease. $B M \mathcal{F} 1956 ; \mathrm{i}: 1523-5$.

33 Woodward M. Small area statistics as markers for personal social status in the Scottish Heart Health Study. $\mathcal{F}$ Epidemiol Community Health 1996;50:570-6.

34 Anderson RT, Sorlie P, Backlund E, et al. Mortality effects of community socioeconomic status. Epidemiology 1997;8:42-

35 Ecob R, Jones K. Mortality variations in England and Wales between types of place: an analysis of the ONS Longitudinal Study. Soc Sci Med (in press).

36 Kaplan GA. People and places: contrasting perspectives on the association between social class and health. Int f Health Serv 1996;26:507-19.

37 Davey Smith G, Hart C, Blane D, et al. Lifetime socio-economic position and mortality: prospective observational study. BMF 1997;314:547-52.

38 Wannamethee SG, Whincup PH, Shaper G, et al. Influence of fathers' social class on cardiovascular disease in middleaged men. Lancet 1996;348:1259-63.

39 Jones K, Moon G. Medical geography: taking space seriously. Progress in Human Geography 1993;17:515-24.

40 Geronimus AT, Bound J, Neidert LJ. On the validity of using census geocode characteristics to proxy individual socio-economic characteristics. Fournal of the American Statistical Association 1996;91:529-37.

41 Firebaugh G. A rule for inferring individual-level relationships from aggregate data. American Sociological Review 1978;43:557-72.

42 Sooman A, Macintyre S, Anderson A. Scotland's health - A more difficult challenge for some? The price and availability of healthy foods in socially contrasting localities in the West of Scotland. Health Bull (Edinb) 1993;51:276-84.

43 Kaplan GA, Pamuk ER, Lynch JW, et al. Inequality in income and mortality in the United States: analysis of mor-
tality and potential pathways. BMF 1996;312:999-1003.

44 Ben-Shlomo Y, White IR, Marmot M. Does the variation in the socio-economic characteristics of an area affect mortality? BMF 1996;312:1013.

45 Kennedy BP, Kawachi I, Prothrow-Stith D. Income distribution and mortality: cross sectional ecological study of the Robin Hood index in the United States. BMf 1996; of the Robin

46 Davey Smith G, Dorling D. "I'm all right John": voting patterns and mortality in England and Wales, 1981-92. BMF 1996;313:1573-7. 